\title{
Performance measures on two-lane highways: Survey of practice
}

\section{Authors: Ahmed Al-Kaisy, Amirhossein Jafari, Scott Washburn, Tapio Lutinnen, and Richard Dowling}

NOTICE: this is the author's version of a work that was accepted for publication in Research in Transportation Economics. Changes resulting from the publishing process, such as peer review, editing, corrections, structural formatting, and other quality control mechanisms may not be reflected in this document. Changes may have been made to this work since it was submitted for publication. A definitive version was subsequently published in Research in Transportation Economics, VOL\# 71, (November 2018), DOI\# 10.1016/j.retrec.2018.07.001.

Al-Kaisy, Ahmed, Amirhossein Jafari, Scott Washburn, Tapio Lutinnen, and Richard Dowling. "Performance Measures on Two-Lane Highways: Survey of Practice." Research in Transportation Economics 71 (November 2018): 61-67. doi: 10.1016/j.retrec.2018.07.001.

Made available through Montana State University's ScholarWorks scholarworks.montana.edu 


\title{
Performance Measures on Two-Lane Highways: Survey of Practice
}

\author{
by Ahmed Al-Kaisy, Amirhossein Jafari, Scott Washburn, Tapio Luttinen and Richard Dowling
}

Two-lane highways constitute a significant component of the highway system and serve an essential function for the movement of people and goods. The Highway Capacity Manual is primarily used for operational analysis on two lane highways in the U.S., Canada and a few other countries outside North America. As part of a project sponsored by the National Cooperative Highway Research Program for improving the two-lane highway operational analysis methodology, a practice survey was conducted to gather information on agency experiences and preferences in regards to performance measurement on two-lane highways. The survey was sent to all state Departments of Transportation (DOTs) in the United States and Canada. A total of 35 usable responses were received, representing 25 states and 4 Canadian provinces, with a few agencies sending multiple responses. This paper summarizes the results of the agency survey and presents the most important findings. Results suggest that the top three criteria for good performance measures on two-lane highways are: sensitivity to traffic conditions, sensitivity to road conditions, and relevance to road user perception. Further, agencies identified average travel speed as the most relevant traffic flow aspect to two-lane highway operations. Other performance measures that were found meritorious were volume-to-capacity ratio and flow rate, for class I and class II highways, respectively, versus average travel speed, volume-to-capacity ratio, and percent-time-spent-following for class III highways.

\section{Keywords: two-lane highways, operational analysis, performance measures, survey.}

\section{INTRODUCTION}

Two-lane highways constitute the vast majority of the highway system in the United States, measured in centerline miles. Most of these highways exist in rural areas and are generally characterized by low traffic volumes, relatively high speeds and lower design standards compared to those used on well-travelled multilane highways. On these highway facilities, a single lane is provided for travel in each direction, resulting in a higher level of interaction between vehicles traveling in the same direction, and often the opposing direction as well. Specifically, maintaining a desired speed is dependent on the ability to pass slower vehicles, which in turn is a function of oncoming traffic level and available sight distance. The interaction between vehicles is also expected to increase with the increase in traffic flow and speed variation associated with a heterogeneous traffic mix. These operational characteristics typically result in formation of platoons and make the platooning phenomenon an important indicator of performance on two-lane highways.

Performance measures are essential for assessing the quality of service, which describes how well a transportation facility or service operates from a traveler's perspective (TRB 2010). From a highway agency's perspective, performance measures are essential in determining the need for operational improvements on two lane highways (e.g., passing lanes) or the need to upgrade to a multi-lane highway. 


\section{HIGHWAY CAPACITY MANUAL PERFORMANCE MEASURES}

The current Highway Capacity Manual (HCM) (TRB 2016) classifies two-lane highways into three different classes based on the degree to which they serve mobility and the adjacent land use character (e.g., rural versus developed areas). These classes are:

a. Class I two-lane highways: Highways where motorists expect to travel at relatively high speeds and they include major intercity routes, daily commuter routes, and major links in state or national highway network.

b. Class II two-lane highways: Highways where motorists do not necessarily expect to travel at high speeds and they include access routes to class I facilities, some scenic and recreational routes, and routes passing through rugged terrain.

c. Class III two-lane highways: These primarily include highways serving moderately developed areas. They may be portions of class I and class II highways that pass through small towns or developed recreational areas.

Traffic stream characteristics on each of these highway classes are different and as such different performance measures are proposed. A total of three performance measures are used in the current HCM analysis methodology for the assessment of level of service (hereafter referred to as service measures), namely: percent time spent following (PTSF), average travel speed (ATS), and percent of free flow speed (PFFS). PTSF is defined as the average percent of total travel time that vehicles must travel in platoons behind slower vehicles due to the inability to pass (TRB 2016). PTSF represents the freedom to maneuver and the comfort and convenience of travel and is used on class I and class II two-lane highways (TRB 2016). While this performance indicator may relate well to the quality of service on two-lane highways, it is impractical to measure in the field. Therefore, the HCM recommends the use of a surrogate measure, referred to in this study as percent followers (PF), for field estimation of PTSF. PF is defined as the percentage of vehicles in the traffic stream with time headways smaller than 3 seconds. ATS on the other hand reflects mobility and is defined as the highway segment length divided by the average travel time taken by vehicles to traverse it during a designated time interval (TRB 2016). ATS is considered for estimating performance on class I two-lane highways only. Finally, PFFS represents the ability of vehicles to travel at or near the posted speed limit and is measured as the ratio of ATS to free flow speed (FFS) multiplied by 100 (TRB 2016). PFFS is used as the service measure only for class III two-lane highways.

Limitations in the HCM methodology for measuring performance on two-lane highways have been reported in several studies and some of those limitations are concerned with the appropriateness of the service measures used (Al-Kaisy and Freedman 2011, Al-Kaisy and Freedman 2010, Al-Kaisy and Karjala 2008, Brilon and Weiser 2006, Luttinen 2001). Specifically, the PTSF is difficult to measure in the field and does not readily describe the extent of congestion on the facility, which is important for operational analysis and highway improvement decisions. Average travel speed, on the other hand, is easy to measure in the field; however, it is not very sensitive to traffic level on the highway. Since the analysis section of a two-lane highway facility is usually several miles long, there could be many changing conditions, such as posted speed limit and roadway alignment that affect ATS, yet it is not related to varying traffic conditions. This can make ATS somewhat meaningless for determining how the highway is operating (Al-Kaisy and Freedman 2011). The PFFS is meant to account for the limitations of ATS as it measures the speed reduction due to increased traffic volume and/or platooning, which makes it possible to compare the current conditions to the ideal conditions (Al-Kaisy and Freedman 2011). One of the limitations of PFFS is that it is largely unaffected by the addition of a passing lane, which indicates that it is not particularly helpful in capturing the delay caused by platooning (Al-Kaisy and Freedman 2010). 
The current study aims at achieving an understanding of U.S. state and Canadian province transportation agencies' perception of the applicability of various performance measures for the analysis of two-lane highways. Specifically, the research presented in this paper attempts to determine what constitutes a good performance measure for two-lane highways from the perspective of the transportation agencies. This information is critical in identifying the most appropriate service measure(s) to be used in an improved two-lane highway operational analysis methodology.

\section{PERFORMANCE MEASURES ON TWO-LANE HIGHWAYS: PRACTICE SURVEY}

In order to better understand the transportation agencies' perceptions and preferences with regard to performance measures on two-lane highways, an online survey was designed as part of the NCHRP Project 17-65. The survey was sent to all state DOTs and to the ministries of transportation in all Canadian provinces. The survey subjects were transportation engineers with key role in evaluating two-lane highway operations in their agencies. As might be expected, these engineers represent the technical expertise in two-lane highway operations within their agencies, and as such, largely represent the agencies' perspective on the various questions included in the survey. The survey included a total of 17 questions, some of which are concerned with agency practice while others are more concerned with participants' perceptions and preferences. A total of 41 responses were received, representing transportation agencies at 25 states and 4 Canadian provinces. The response rates for the U.S. and Canada were $49 \%$ and $40 \%$, respectively. There were three states with more than one response-Oregon, California and Texas with 4, 3 and 2 responses, respectively. It should be noted that 6 survey subjects submitted the survey without answering any of the questions and therefore, were excluded from the analysis. Figure 1 identifies the responding U.S. states and Canadian provinces.

\section{Figure 1: Survey Participating Agencies in the U.S. and Canada (in gray)}

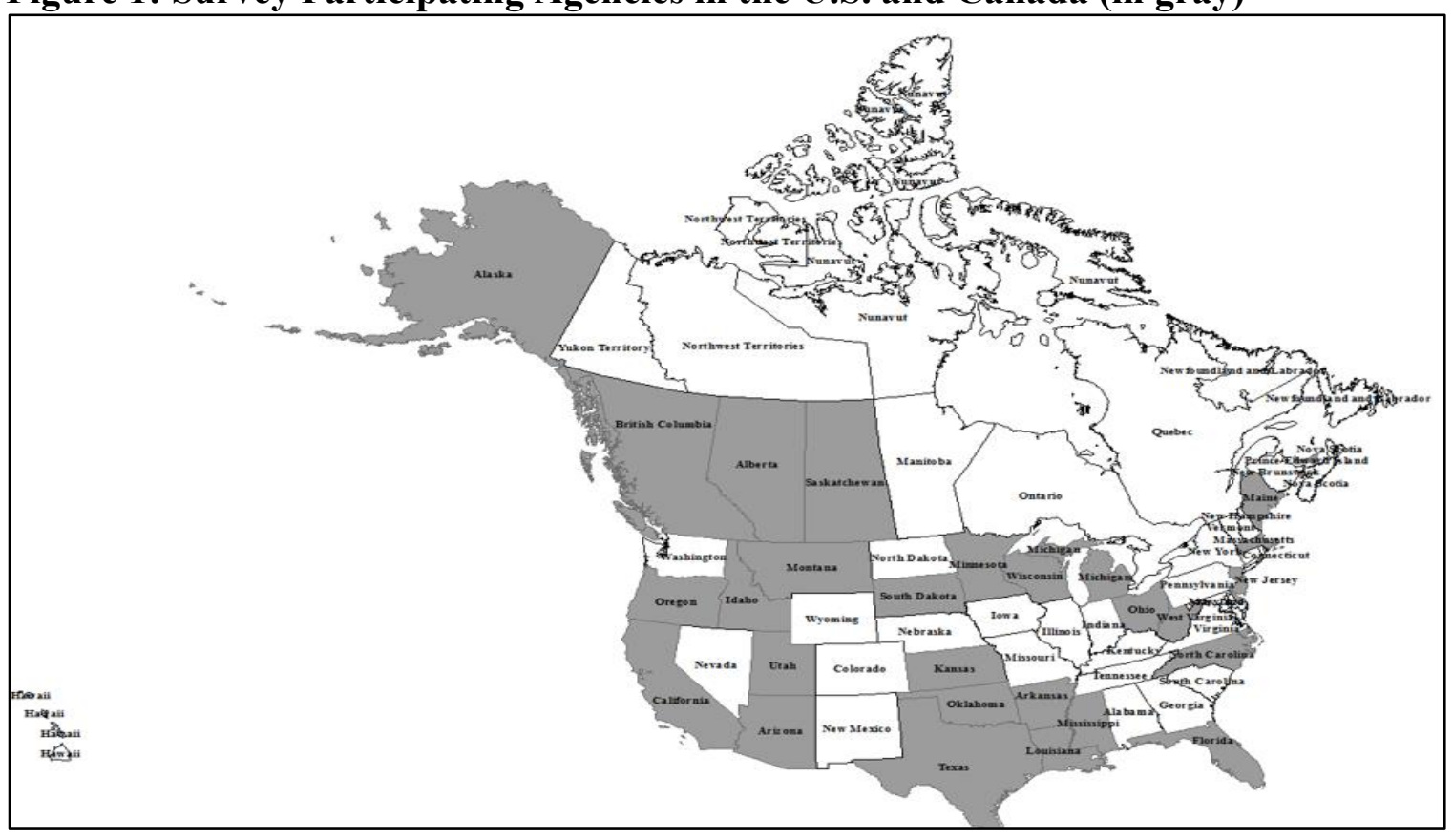




\section{Performance Measures Investigated}

The survey questionnaire included all performance measures that are currently used by the $\mathrm{HCM}$, as well as those from the literature that have been proposed or reported as being used. In general, performance measures for two-lane highways fall into one of the following categories:

Speed-related Measures Several speed-related measures have been used in practice or proposed in the literature for measuring performance on two-lane highways. The current HCM methodology uses ATS for class I two-lane highways and PFFS for class III two-lane highways. The PFFS is defined as the ratio of average travel speed to free-flow speed multiplied by 100. Other speed-related measures include average travel speed of passenger cars, average travel speed of passenger cars as a percentage of free-flow speed of passenger cars (PFFSP) (Al-Kaisy and Karjala 2008, Al-Kaisy et al. 2017, Brilon and Weiser 2006) and speed variance (Luttinen 2001).

Flow-related Measures The transportation agencies' perception of the quality of service and the level of vehicular interaction (following or passing slower vehicles) is believed to be a function of traffic flow. The use of volume-to-capacity (v/c) ratio on two-lane highways was reported as the primary performance measure in Denmark, China and Japan (Vejdirektoratet 2010, Rong et. al 2011, Nakamura and Oguchi 2006) and as a secondary performance measure in Sweden (Trafikverket 2013). Follower flow is another flow-related performance measure which was investigated by the South African National Roads Agency (Van As 2004). Follower flow is defined as the flow rate multiplied by the percentage of vehicles with short headways, that is, headways smaller than a pre-specified threshold value (vehicles assumed to be in following mode).

Density-related Measures Density has been reported as a performance measure used in Germany for two-lane highway analysis (Brilon and Weiser 2006). In this particular application, density is estimated as the ratio of traffic flow (vehicles per hour) to the average speed of passenger cars. Follower density is another measure introduced by the South African National Roads Agency and is calculated as the product of percent followers (PF), defined earlier, and traffic density (Van As 2004).

Headway-related Measures Time headway, which is a microscopic traffic flow characteristic, is another measure used in practical applications as well as in published research. An important measure in this category is PF. Percent impeded (PI) is another measure in this category, which is defined as the product of PF and the probability of desired speeds being greater than the average speed of platoon leaders (Al-Kaisy and Freedman 2011).

Passing-related Measures Limited passing opportunities are believed to contribute to the formation of platoons and increased delay on two-lane highways. Overtaking ratio and the average number of passes per vehicle are two proposed measures in this category (Luttinen 2001, Morrall and Werner 1990, McLean 1989). The overtaking ratio is estimated by dividing the number of passes achieved by the number of passes desired (Morall and Werner 1990).

\section{STUDY RESULTS}

As was mentioned before, the survey included questions about the agency practice as well as other questions that are more related to respondents' perceptions and preferences. A summary of survey results is provided in this section.

\section{Agency Practice}


When asked about the use of HCM 2010 methodology for two-lane highways, all responding agencies in the U.S. and Canada confirmed the use of the HCM methodology, except one state agency. That agency reported the use of crash analysis and Synchro/Simtraffic software packages for their analysis, and the HCM procedures are used as a supplementary tool if more information is required. The aforementioned response does not seem to be accurate, especially since the question is concerned with operational analysis and that Synchro/Simtraffic does not have the capability to model two-lane highway operations. Further, the Interactive Highway Safety Design Model (IHSDM) TWOPAS was mentioned as a supplemental analysis tool besides the HCM by another state. Oregon utilizes follower density for analysis of class I and class II highways; however, the HCM is used for analysis of class III highways.

Survey participants were also asked about the performance measures used by their agency in the operational analysis of two-lane highways. These results are shown in Figure 2.

Figure 2: Performance Measures Used in Two-lane Highway Operational Analysis

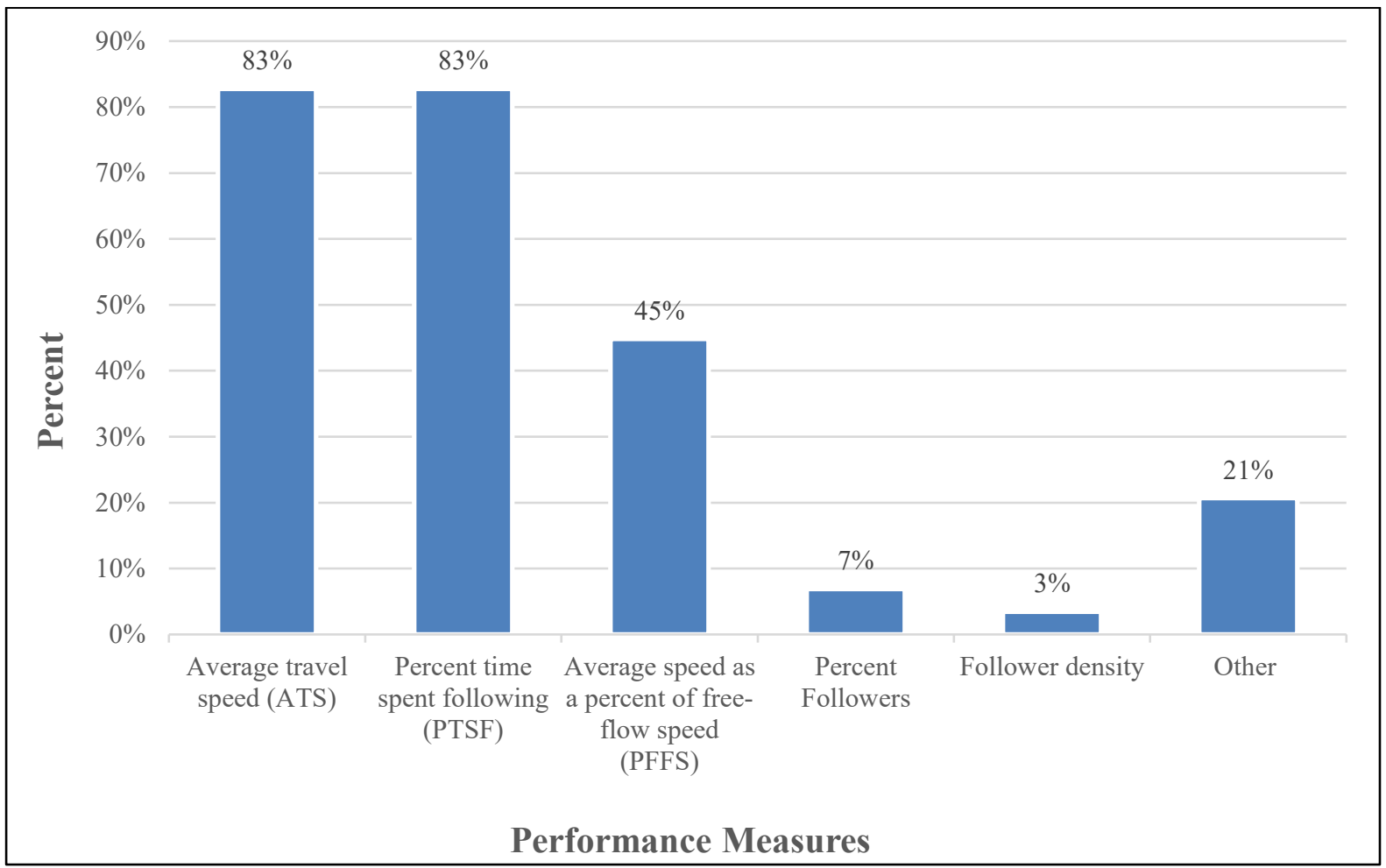

ATS and PTSF, followed by PFFS, are used the most for performance analysis on twolane highways. Only Oregon reported the use of follower density for performance analysis on two-lane highways. Percent followers for vehicles traveling at headways of less than 2 seconds is used by the ministry of Transportation and Infrastructure in British Columbia, Canada. The use of traffic counts, delay, and speed differential for two-lane highway operational analysis was also mentioned by another state agency. Several other performance measures were reported in the survey and they include: annual average daily traffic (AADT), the ratio of AADT to capacity (AADT/c), volume-to-capacity ratio (v/c) and the location and size of available passing areas.

The survey participants were further asked about the data collected by their respective agencies that is used in assessing performance on two-lane highways. The results are summarized in Figure 3. As shown in this figure, almost all highway agencies in the U.S. and 
Canada use binned vehicle counts as part of their regular data collection programs on two-lane highways. Per vehicle data, which is critical in estimating some performance measures on twolane highways, is only collected by $17 \%$ of the responding agencies. This is somewhat expected given the difficulty in storing and handling the large amount of per-vehicle data using older data collection equipment and technologies still in use by many highway agencies. Maine reported the use of speed-delay runs in assessing two-lane highway performance. The Ministry of Transportation and Infrastructure in British Columbia, Canada reported the use of pervehicle data on two-lane highways on an ad-hoc basis.

\section{Figure 3: Traffic Data Collected by Highway Agencies for Assessing Performance}

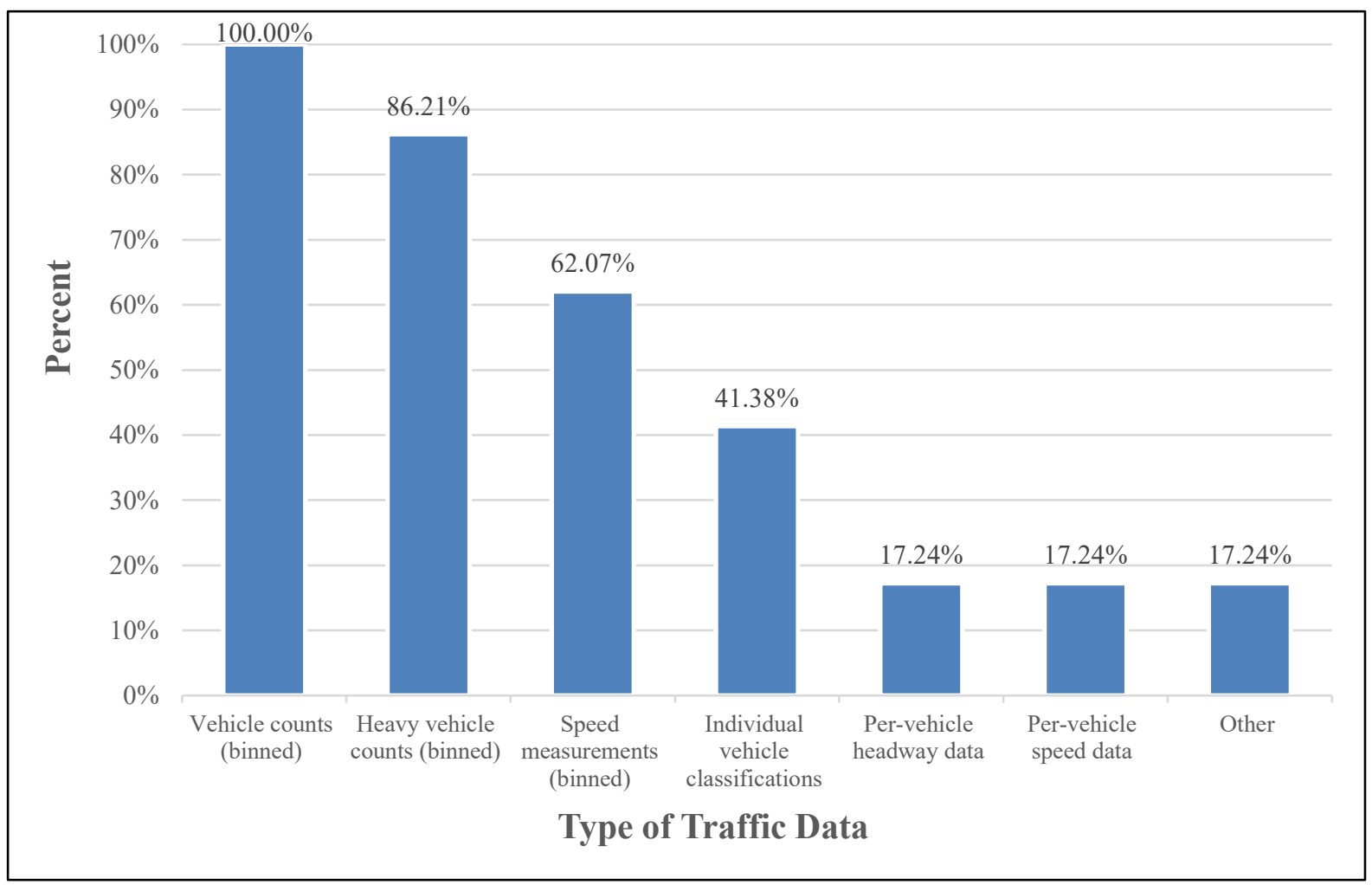

\section{Practitioners' Perception of Two-Lane Highway Performance Measures}

Some of the survey questions ask about the participant opinion of the various aspects related to performance measures on two-lane highways. As was mentioned before, there were a total of 35 responses representing 25 states and 4 Canadian provinces. For the analysis of these questions, all responses are considered even if multiple responses came from the same agency, as those responses are more related to individuals' opinions. A discussion of these questions and their responses is provided below.

One survey question attempted to gain a better understanding of what constitutes a good performance measure for two-lane highways. Several characteristics of performance measures were identified in this survey and participants were asked to rank these characteristics based on their relative importance for each class of two-lane highways. The characteristic with the highest importance was given a rank of ' 1 ' and the rank increases with the decrease in importance. A summary of the participants' rankings is presented in Figure 4 for the three classes of two-lane highways. 
As shown in this figure, the most important characteristic in a two-lane highway performance measure is being sensitive to traffic conditions, as perceived by survey participants. The second characteristic in importance is being sensitive to road conditions.

\section{Figure 4: Average Ranking for Characteristics of Performance Measures}

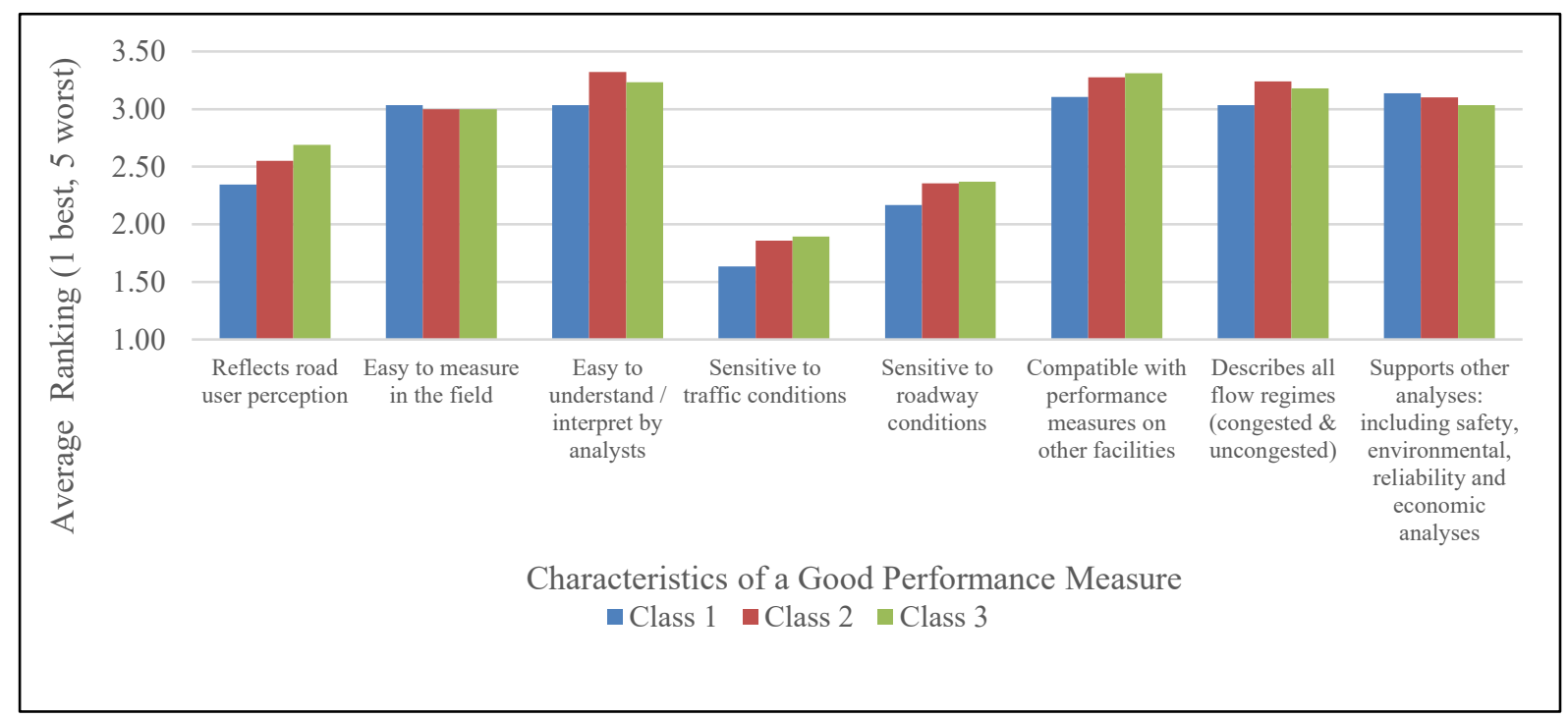

Road conditions on two-lane highways include such features as horizontal and vertical alignment, lane width and shoulder width. Road user perception of the quality of ride is the third most important characteristic in a performance measure, as ranked by survey participants. The remaining characteristics of performance measures were ranked almost the same with an average ranking of around 3.0. Rankings for different classes of two-lane highways were largely similar, particularly for the three most important characteristics discussed earlier, as clearly shown in Figure 4.

Another survey question asked participants to rank several aspects of traffic flow with respect to their usefulness in assessing performance on two-lane highways. Figure 5 summarizes the responses to this question, with the lowest rank representing the most useful traffic flow aspect, and vice versa.

Figure 5: Average Ranking Score of Traffic Flow Aspects

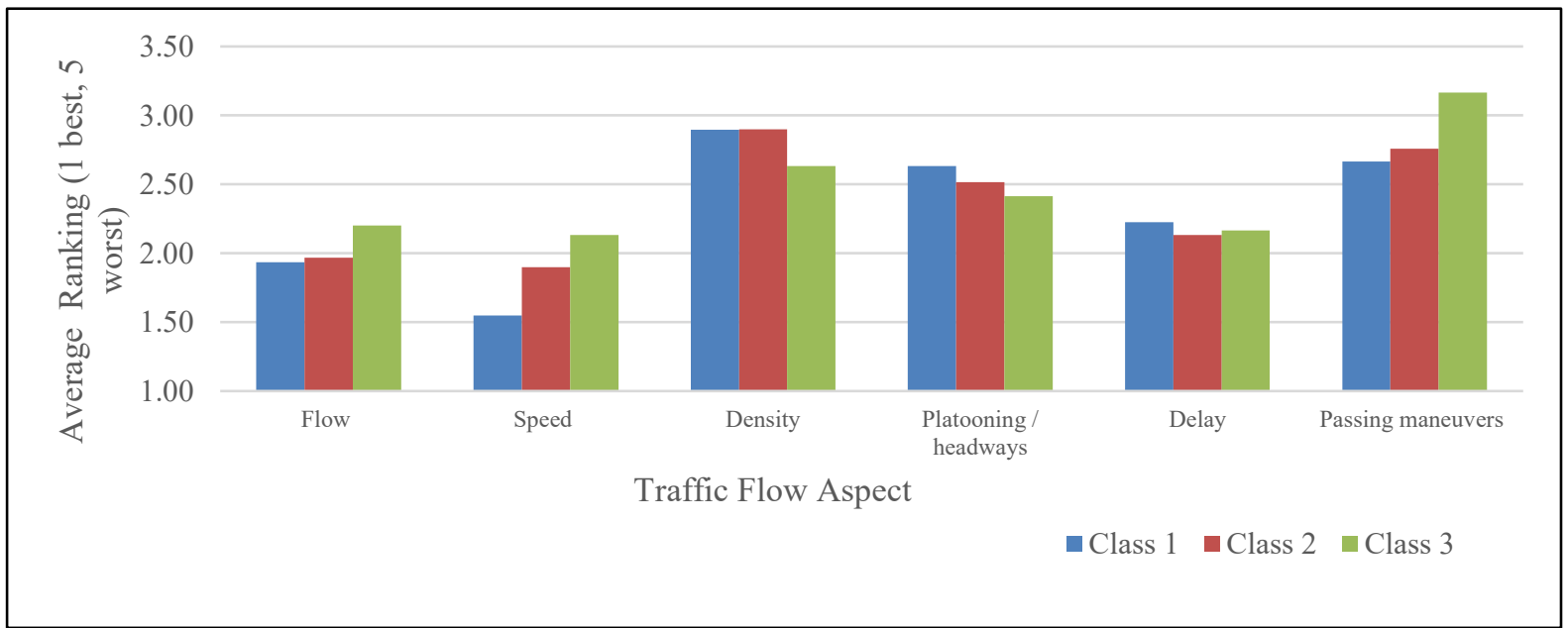

As Figure 5 depicts, speed was ranked as the most useful aspect of traffic flow in assessing performance on two-lane highways. The rankings for class I and class II highways 
are almost identical with the most useful traffic flow aspects ranked in the following order: speed, flow, delay, headways, passing maneuvers and density. The corresponding ranking for class III highways resulted in the following order: speed and delay, followed by flow, headways, density and passing maneuvers respectively. The latter ranking is logical given the fact that delay is an important performance measure for interrupted traffic streams and that passing maneuvers may not represent an important aspect of traffic operations in relatively developed areas where major driveways, intersections and auxiliary turning lanes exist.

The survey questionnaire presented the participants with a series of questions asking about the most appropriate two-lane highway performance measures, in relation to those traffic flow aspects discussed in the previous question. Table 1 presents the average rankings for each performance measure grouped by different traffic flow aspects (a rank of 1.0 represent the best performance measure).

Table 1: Average Ranking Score for Performance Measures

\begin{tabular}{|c|c|c|c|c|}
\hline \multirow{2}{*}{$\begin{array}{c}\text { Traffic Flow } \\
\text { Aspect }\end{array}$} & \multirow{2}{*}{ Performance Measure } & \multicolumn{3}{|c|}{ Average Ranking Score } \\
\hline & & Class I & Class II & Class III \\
\hline \multirow{3}{*}{ Flow } & Volume-to-Capacity (v/c) Ratio & $\underline{1.56}$ & $\underline{1.52}$ & $\underline{1.63}$ \\
\hline & Flow Rate & 1.61 & 1.74 & 1.77 \\
\hline & Follower Flow (FF) & 2.14 & 2.09 & 2.23 \\
\hline \multirow{5}{*}{ Speed } & Average Travel Speed (ATS) & $\underline{1.54}$ & $\underline{1.52}$ & $\underline{1.65}$ \\
\hline & $\begin{array}{c}\text { Average Travel Speed as a Percent of } \\
\text { Free-Flow Speed (PFFS) }\end{array}$ & 2.12 & 2.20 & 2.09 \\
\hline & $\begin{array}{c}\text { Average Travel Speed of Passenger Cars } \\
\left(\text { ATS }_{\mathrm{PC}}\right)\end{array}$ & 2.44 & 2.31 & 2.43 \\
\hline & Speed Variance & 2.33 & 2.56 & 2.58 \\
\hline & $\begin{array}{c}\text { ATS }_{\text {PC }} \text { as a Percent of Free-Flow Speed } \\
\text { of Passenger Cars (PFFS }\end{array}$ & 2.84 & 2.92 & 3.10 \\
\hline \multirow{2}{*}{ Density } & Traffic Density & 1.44 & $\underline{1.56}$ & 1.85 \\
\hline & Follower Density (FD) & $\underline{1.38}$ & 1.61 & $\underline{1.65}$ \\
\hline \multirow{4}{*}{$\begin{array}{l}\text { Platooning / } \\
\text { Headways }\end{array}$} & Average Platoon Length (\# of vehicles) & 2.29 & 2.35 & 2.53 \\
\hline & Percent Time Spent Following (PTSF) & $\underline{1.44}$ & $\underline{1.61}$ & $\underline{1.89}$ \\
\hline & Percent Followers (PF) & 2.19 & 2.31 & 2.44 \\
\hline & Percent Impeded (PI) & 2.29 & 2.41 & 2.41 \\
\hline \multirow{2}{*}{$\begin{array}{l}\text { Passing } \\
\text { Maneuvers }\end{array}$} & Overtaking Ratio & $\underline{1.15}$ & $\underline{1.42}$ & $\underline{1.91}$ \\
\hline & Average Number of Passes per Vehicle & 1.83 & 2.00 & 2.30 \\
\hline
\end{tabular}

Bold underlined values represent the best average ranking for each class by traffic flow aspect

The relative rankings shown in Table 1 suggest a high level of consistency across the three classes of two-lane highways. Among flow-related performance measures, v/c ratio was ranked first followed by traffic flow and FF, respectively. With regard to speed-related measures, average travel speed was ranked first, followed by average travel speed as a percent 
of free-flow speed (PFFS), average travel speed of passenger cars (ATS PC , speed variance and $\mathrm{ATS}_{\mathrm{PC}}$ as a percent of free-flow speed of passenger cars $\left(\mathrm{PFFS}_{\mathrm{PC}}\right.$ ) respectively. For densityrelated measures, traffic density is perceived as a better performance measure on class II highways, while follower density (FD) is perceived as a better measure on class I and class III highways. For headway-related performance measures, the HCM measure percent-time-spentfollowing (PTSF) is perceived the best followed by percent followers (PF), percent impeded and average platoon length respectively. PF is used in the current HCM as a surrogate measure for estimating PTSF using field data. Finally, for measures related to passing maneuvers, overtaking ratio is perceived as a better performance measure compared to the average number of passes per vehicle on a two-lane highway segment.

While Table 1 is useful in comparing performance measures that belong to the same group/category, it cannot be used to provide objective comparisons across categories. Specifically, the number of measures in each group is different, and therefore, the same average ranking in two different groups could indicate different levels of merit.

When asked about their satisfaction with the HCM performance measures, around $73 \%$ of the agencies surveyed mentioned they were satisfied with HCM performance measures used by their agencies. Several issues were raised by survey participants, which corresponded to what they perceive as limitations in the current performance measures used on two-lane highways. Some of the comments made in this regard are as follows:

- PTSF is difficult to measure in the field.

- The level of service based on PTSF is overestimated, especially in summer peak traffic, in that everyone is following someone else.

- Even if all vehicles are driving at speeds near speed limit or above, level of service based on PTSF would be F.

- The PTSF does not recognize or rate context of a project segment within an entire corridor between control cities.

- For class 1 highways with high volume, the PTSF dictates the LOS results; however the HCM suggests using both the ATS and the PTSF for class 1 highways.

As was mentioned earlier, there are some limitations related to the HCM 2000 methodology for operational analysis of two-lane highways (TRB 2000) as reported in several studies in the literature (Al-Kaisy and Freedman 2011, Al-Kaisy and Freedman 2010, Al-Kaisy and Karjala 2008, Brilon and Weiser 2006, Luttinen 2001). This methodology has not significantly changed in the later HCM editions (TRB 2010, 2016). Survey participants were asked to state their priorities for revisions/additions to the HCM two-lane highway analysis methodology. The following is a summary of their feedback as related to the use of performance measures on two-lane highways.

A few characteristics were mentioned by survey participants as being important for a good performance measure on two-lane highways. One respondent mentioned that the performance measure should be able to describe the whole corridor between control cities/towns. Overall travel time was mentioned as an example of such performance measures. Other respondents suggested the use of other measures not included in the survey such as travel time reliability. One survey respondent mentioned that the travelers' experience along the whole corridor should be considered by any proposed new measure. Replacing PTSF and ATS with more follower (headway) based measures like follower density was recommended by another survey respondent. Other criteria that were mentioned by survey participants as being important for performance measures are consistency between facilities in different area types (urban, suburban, rural) and the ease with which the measures can be explained to the public. 


\section{SUMMARY OF FINDINGS}

In an attempt to better understand the transportation agency's perspective with regard to what constitutes a good performance measure for two-lane highways, a questionnaire survey was sent to all state DOTs in the U.S. and the provincial ministries of transport in Canada. The survey also included a few questions about the agency experience with the use of the HCM and proposed changes and revisions to the current analytical procedures. A total of 35 usable responses were received, representing transportation agencies at 25 states and 4 Canadian provinces. The most important findings of the survey on the use of two-lane highway performance measures are summarized below:

- Almost all highway agencies reported the use of the current HCM performance measures on two-lane highways, i.e., average travel speed, percent-time-spentfollowing, and percent of free flow speed. Among other non-HCM measures used by some agencies were follower density, percent follower for vehicles traveling at headways of less than 2 seconds, traffic flow, delay, v/c ratio and AADT/c ratio.

- While almost all highway agencies in the U.S. and Canada use binned vehicle counts as part of their regular data collection programs on two-lane highways, per vehicle data, which is critical in estimating some performance measures on two-lane highways, is only collected by $17 \%$ of the responding agencies. This restricts the ability of those agencies in using many performance measures included in this survey, which require the more detailed per vehicle data.

- The top three criteria that were ranked as being most important characteristics for twolane highway performance measures are: sensitivity to traffic conditions, sensitivity to road conditions, and relevance to road user perception, respectively.

- Among traffic flow aspects that are most relevant to two-lane highway operations, speed followed by flow were ranked as the most important aspects for all two-lane highway classes.

- With regard to the merit of using individual performance measures within each traffic flow aspect category, the best measures were found to be v/c ratio, average travel speed, PTSF, and overtaking ratio for all two-lane highway classes in the flow, speed, headways and passing maneuvers categories respectively. For the density flow aspect, follower density was found superior on class I and class III while density was found superior on class II two-lane highways. Percent followers, used by the current HCM as a surrogate measure for PTSF, was associated with much lower average ranking compared with PTSF for all highway classes.

The responses to the practice survey included some of the limitations of the current HCM performance measures from the agencies' perspective, as well as some valuable suggestions and feedback on two-lane highway performance measures that were discussed in the paper. This information is expected to help in the selection of the most appropriate performance measure(s) for use in future methodologies of two-lane highway operational analysis.

\section{References}

Al-Kaisy, A., and S. Karjala. "Indicators of Performance on Two-Lane Rural Highways: An Empirical Investigation". Transportation Research Record: Journal of the Transportation Research Board, No. 2071, (2008): 87-97. 
Al-Kaisy, A., and Z. Freedman. "Empirical Examination of Passing Lane Operational Benefits on Rural Two-Lane Highways". Journal of Transportation Research Forum, Vol. 49, No. 3, (2010): 53-68.

Al-Kaisy, A., and Z. Freedman. "Estimating Performance on Two-Lane Highways: Case Study Validation of a New Methodology". Transportation Research Record 2173, Journal of the Transportation Research Board, (2011): 72-79.

Al-Kaisy, A., Jafari, A., S. Washburn, S., Lutinnen, T., and R. Dowling. "Performance Measures on Two-Lane Highways: Survey of Practice". Presented at the 95th Annual Meeting of the Transportation Research Board, Washington D.C, (2016).

Al-Kaisy, A., Jafari, A., S. Washburn. "Measuring Performance on Two-Lane Highways: Empirical Investigation". Transportation Research Record 2615, Journal of the Transportation Research Board, (2017): 62-72.

Brilon, W., and F. Weiser. "Two-Lane Rural Highways: The German Experience". Transportation Research Record 1988: Journal of the Transportation Research Board, (2006): $38-47$.

Luttinen, R. T. "Percent Time Spent Following as Performance Measure for Two-Lane Highways". Transportation Research Record 1776, Journal of the Transportation Research Board, (2001): 52-59.

McLean, J. "Two-Lane Highway Traffic operations: Theory and Practice". Transportation Studies Volume 11, Gordon and Breach Science Publishers, (1989).

Morrall, J. F., and A. Werner. "Measuring Level of Service of Two-Lane Highways by Overtakings". Transportation Research Record 1287, Journal of the Transportation Research Board, (1990): 62-69.

Nakamura, H. and T. Oguchi. "An Overview on Capacity and Quality of Service Studies in Japan". Proceedings of the 5th International Symposium on Highway Capacity and Quality of Service. Vol.1: Country Reports and Special Session Papers. Tokyo: Japan Society of Traffic Engineers, (2006): 87-104.

Rong, J., Guo, J. and R. Zhou. "Chinese Highway Capacity Research Studies and Applications". In Koutsopoulos, H.N. and Bang, K.L. (ed.), 6th International Symposium on Highway Capacity and Quality of Service - Country Reports. Stockholm: TRB and KTH, (2011): 52-66.

Trafikverket. “TRVMB Kapacitet och framkomlighetseffekter”. TRV 2013:64343, (2014).

Transportation Research Board. "Highway Capacity Manual”. Fourth Edition, TRB, National Research Council, Washington, D. C., (2000).

Transportation Research Board. "Highway Capacity Manual". Fifth Edition, TRB, National Research Council, Washington, D. C., (2010).

Transportation Research Board. "Highway Capacity Manual". Sixth Edition, TRB, National Research Council, Washington, D. C., (2016). 
Van As, C. and A. Niekerk. "The Operational Analysis of Two-Lane Rural Highways". Proceedings of the 23rd Annual Southern African Transport Conference, Pretoria, South Africa, 12-15 July, (2004).

Vejdirektoratet. "Kapacitet og serviceniveau. Vejdirektoratet", Vejregelrådet. - Road Standards for Capacity and Level of Service, (2010). (in Danish)

\section{Acknowledgements}

The authors would like to acknowledge the financial support provided for this study by the National Cooperative Highway Research Program. Further, the authors would like to thank the respective staff at participating agencies for taking the time to complete the survey described in this study.

Dr. Ahmed Al-Kaisy is a transportation engineering professor in the Department of Civil Engineering at Montana State University. His primary research and teaching interests include traffic flow theory, traffic control and optimization, capacity and quality of service, highway geometric design and traffic safety. Dr. Al-Kaisy holds a doctoral degree in transportation engineering from Queen's University in Ontario, Canada.

Dr. Amirhossein Jafari received a M.Sc. degree in transportation engineering from Sharif University of Technology in 2012, and a B.Sc. in civil engineering from the Isfahan University of Technology in 2010. He received his PhD in transportation engineering from Montana State University in 2018. His graduate research is in the area of traffic performance on two-lane highways.

Dr. Scott Washburn is a Professor in the Department of Civil and Coastal Engineering at the University of Florida. Dr. Washburn's areas of expertise include traffic flow theory, traffic operations analysis, traffic simulation model development and testing, development of traffic analysis and level of service computational methodologies and complementary software tools. $\mathrm{He}$ is also a registered professional engineer in the states of Washington and Florida and is coauthor of the textbook "Principles of Highway Engineering and Traffic Analysis".

Dr. Tapio Lutinnen is a professor of transportation engineering in Aalto University, Finland. His teaching and research interests include stochastic modelling of traffic flow as well as transportation policy and economics. He holds a doctoral degree and a master's degree in engineering from Helsinki University of Technology, Finland.

Dr. Richard Dowling is a licensed Professional Engineer in the states of California and Florida. He has over 40 years of experience in transportation planning, traffic engineering operations, research and education as a municipal employee and as a consultant. Dr. Dowling has been the principal investigator for several NCHRP research projects related to truck level of service; planning applications of the Highway Capacity Manual; traffic signal coordination, predicting the long term air quality impacts of capacity improvement projects, and multimodal level of service for urban streets. 